\title{
A!
}

This is an electronic reprint of the original article.

This reprint may differ from the original in pagination and typographic detail.

Jaatinen, Miia; Lavikka, Rita

\section{Common understanding as a basis for coordination}

\author{
Published in: \\ Corporate Communications
}

Published: 01/01/2007

Document Version

Peer reviewed version

Please cite the original version:

Jaatinen, M., \& Lavikka, R. (2007). Common understanding as a basis for coordination. Corporate Communications, 12.

This material is protected by copyright and other intellectual property rights, and duplication or sale of all or part of any of the repository collections is not permitted, except that material may be duplicated by you for your research use or educational purposes in electronic or print form. You must obtain permission for any other use. Electronic or print copies may not be offered, whether for sale or otherwise to anyone who is not an authorised user. 


\title{
Common understanding as a basis for coordination
}

\begin{abstract}
Purpose - to develop further a theoretical framework of common understanding and explore the role of common understanding in coordination

Methodology/approach - a constructive action research approach applying abductive reasoning to develop new models with practical relevance

Findings - a new framework of the elements of common understanding and a new theory of communication as a mechanism for coordination

Research limitations/implications - a longitudinal case study as part of a multiple casestudy, findings generalized to theory which should be further developed

Practical implications - a framework for developing shared meanings to achieve better coordination in collaborative service provisioning

Originality/value - a new model of common understanding, a refined approach to coordination
\end{abstract}

Key words - common understanding, sense-making, coordination, networked business, communication

Paper type - Research paper

\section{Introduction}

In the networked economy, companies create added value by forming alliances and collaborating with other companies in the value chain. However, networked business with its many relationships poses challenges to the different parties. One of the most important challenges for the management of networked business is the task of 
coordination. When the planning, production, and sales of products and services are distributed to different organizations, the interdependences must be managed in order to bring added value to each of the collaborators as well as the end-customers.

In addition to the magnified need for coordination, different mechanisms of coordination are emphasized in the networked business. Networks defy control, the traditional means for coordination. In networks, no one is in the position to command others which is why direct supervision and hierarchy does not work. Networks consist of organizations that have different cultures. Therefore, culture is not an automatic tool for coordination. In temporary project organizations, there are no routines or rules. Thus, communication takes a central role in coordinating networked business. It can provide a common frame of reference and a process to create it. Despite the pivotal role of communication, scientific research gives no other than structural answers to how to coordinate with communication. In a chaotic environment it is not enough to increase communication and information processing. What is needed, is a common framework for interpretation which can be created, maintained, and changed by communication. Our research findings support the idea that coordination of meanings is a suitable method for coordination in networked business. The creation of common understanding about common business provides a common frame of reference that guides partners in their actions.

We observed the process of developing coordination mechanisms for networked service provisioning in our case organizations during two consecutive simulation projects in the Fall 2004 and Spring 2005. The case focused on two business units of a publisher corporation serving the same clients. The research objective for the first simulation project was to develop further the theoretical framework of common understanding 
presented by Mäkelä (2002) whereas the objective for the second project was to explore the role of common understanding in coordination. In this paper, we describe first how the creation or lack of common understanding influences collaboration and secondly, how our case organizations planned to coordinate their activities. The paper discusses how the creation of common understanding plays an important role in coordinating networked operations.

The study is part of an action research based multiple case study conducted in SimLab that is a multidisciplinary research and teaching unit of the Helsinki University of Technology $(\mathrm{TKK})$. The laboratory applies the $\operatorname{SimLab}^{\mathrm{TM}}$ business process simulation method in the development and training projects conducted with the pilot-organizations.

\section{Sense-making as the foundation of common understanding}

Companies and company networks engage in a continuous process of sense-making. Companies interpret the business environment and select an appropriate course of action. According to Weick (1979), sense-making consists of a three-step process of enactment, selection, and retention. First, an organization detects a change in the environment which starts an effort to understand its significance. Organizations gather and organize data from the environment. In this enactment process, organizations actively construct the environments they attend to. This data is, then, evaluated based on earlier experiences and their interpretations during the selection process which will finally attach meaning to the data. The enacted environment provides an explanation of what has happened, i.e., what is the relationship between events and actions. During the retention process, the enacted environment is stored for future use. In Weick's (1995) terms, sense-making is 
about identity construction. It is retrospective, active, continuous, and social. It is initiated by cues and aims at plausible explanations.

Sense-making produces sensible structures that can be used as frames of reference when a new situation is encountered and a new cue requires interpretation (Weick, 1995). According to Choo (1998), sense-making produces shared meanings and understandings on the environment, identity, and actions of the organization. Members of an organization can use these shared meanings and understandings to coordinate their actions. Even though these meanings are and should be continuously recreated and renewed, they provide some degree of consensus that helps people relate their actions. We call this consensus common understanding following Mäkelä (2002) who also presented the original framework for common understanding developed further in this study.

\section{Common understanding and communication}

According to Mäkelä (2002), common understanding consists of shared meanings that are created through communication or shared experiences. Common understanding is composed of five elements or content categories: 1) shared ways of thinking, 2) shared ways of operating, 3) shared knowledge, 4) shared goals, and 5) trust.

Shared ways of thinking include common concepts, language, symbols, norms, and values. Shared ways of operating means agreement between partners on the roles and responsibilities, the common processes, and methods applied. Shared knowledge concerns the object and content of collaboration, i.e., what we are doing and how it should be done. Shared goals include common objectives and expectations as well as partners' own objectives and expectations. Trust is based on the beliefs partners have of each other's capabilities and characteristics (Mäkelä, 2002). 
Mäkelä (2002) states that common understanding is created in the process of communication within a context of culture by sharing knowledge. Communication is defined as the process of creating, maintaining, and changing meanings in a certain context (Aula, 1999). Knowledge is a justified true belief about action leading to some end. Knowledge conveys meaning, and it is created in social interaction (Nonaka and Takeutchi, 1995). There is a recursive relationship between communication and common understanding (Aula, 2000). As a result of communication, shared meanings constituting common understanding are created. The forming common understanding affects back to the process of communication.

This theory is based on the notion of culture as consisting of shared meanings and common understanding. This is also applicable to a network context. The culture of a network is created by the community of practice that is composed of people collaborating in the network.

Communities of practice create concepts, symbols, tools, procedures, and world views that serve action (Wenger, 1998). Shared understandings of the common goal and how to respond to it are required for acting coordinated in a community of practice. According to Wenger (1998), communities of practice achieve coordination by localizing or locating. Localizing involves delegation and prescription whereas locating is achieved through communication which connects different parts together. Communities of practice can also be thought of as shared histories of learning. They learn to respond to a common challenge and they can reinvent the practice as conditions change.

Common understanding is a kind of ideal state or goal to which collaborators are striving. Czarniawska-Joerges (1992) states that coordinated action does not require common 
meanings. It is enough to share meanings partly or share the experience of collective action. Common meanings are a kind of anomaly because reality is enacted and changing. It is difficult even to achieve shared meanings. Weick (1995) suggested that people have to make sense of their common experience together soon after its occurrence and create a common interpretation of it in order to create shared meanings.

In our study, the two simulation projects provided a forum for communication to create common understanding between the two business units starting collaboration. Since the practical development objective and our research interests met each other, we had a chance to observe and participate in the planning of this communication.

\section{Common understanding as a mechanism of coordination}

The challenge of coordination is related to organizational structure. The need for coordination arises as organizations become more and more decentralized. When a task is divided and delegated to more than one actor, someone or something is needed to integrate the separate actions to ensure task completion and output quality. In networks, complete business processes can be delegated to many organizations that aim at profit for each member. A widely accepted definition is that coordination is about integrating different parts of the organization in order to achieve a common goal (Lawrence and Lorsch, 1967).

Mintzberg (1979) provided five mechanisms of coordination which are introduced in the following order as the complexity of an organization increases: mutual adjustment (in small organizations), direct supervision, standardization of work, output or skills, and mutual adjustment again (in complex operational environments, e.g., in project organizations). In a small organization, the division of labor is minimal and everybody 
knows the tasks and adapts to each other informally. Direct supervision is needed when there are more than five or six people and informal communication is not enough for achieving coordination. The supervisor takes the responsibility for the work of others, provides leadership, and controls performance. Standardization of work is introduced with increasing organizational size when tasks remain simple and routine. When task complexity increases there is a shift to standardization of output. People are left the choice of how to get the work done. In expert organizations the tasks are so complex that standardization has to focus on skills, which means specification of training required. When the size of the organization increases, it needs to revert to mutual adjustment again. In Mintzberg's classification, mutual adjustment consists of informal communication between those who perform the work. According to Mintzberg, informal communication is very important for task accomplishment but his solutions are structural in the end, consisting of lateral linkages and grouping people into work constellations. We believe that in big organizations, employees start loosing the big picture which is why communication can become an important means of coordination. Through communication the big picture can be created again and shared in the organization. This requires shared meanings, not just more frequent communication for adaptation.

According to Perrow (1986), organizational design does not solve the problem of coordination alone and lots of work gets done even though it is not regulated by rules and commands. Perrow suggests that organizations should extend control to decision premises and flow of information. Premise controls are unobtrusive controls. Once people have internalized the premises, they voluntarily apply them in defining a situation or problem, in the search for alternatives, and in the selection of solutions. 
Culture is an important source of premise control. When people become members of a culture, they learn the language, beliefs, and values of the culture and start interpreting the reality in the same way as others. Coordination of interpretations is achieved through communication with other members of the culture. To the extent that a dominant culture is accepted and persuasive, it can provide a mechanism for control. Control by culture is not necessarily exerted by management. Alternatively, people themselves can choose the culture and comply with its norms voluntarily (Conrad, 1994; Conrad and Poole, 2002). Cultures control members through shared assumptions that lead to similar behaviours. Cultures are built in a process of external adaptation and internal integration based on shared experiences of success (Schein, 2004).

Common understanding created in the process of collective sense-making is a representation of the forming culture of the network community of practice. The sensemaking approach emphasizes how companies can better understand environmental change and create purposeful ways of responding to that change. It provides a coherent description of how organizations learn to survive and innovate. We believe that coordination by creating shared meanings through communication is an effective way to cope with the ever increasing speed of change. When collaborators have a common understanding on the premises and processes of their common business, it is easier to fit processes together and act coordinated. Thus, organizations should focus on how people create consistent understandings on the choices made concerning strategy, organization, and resources and use this understanding in problem-solving.

\section{Case description}


We studied a case defined by two business units of a Finnish publishing corporation. The units are serving partly the same clients, the teachers at comprehensive schools. One provides an e-learning environment for the teachers, pupils, and rectors of the comprehensive schools in Finland, and the other publishes and sells school books and support materials. The two business units have separate business models and some different customers which is a reason why these two units cannot simply be reorganized as one unified process and organization. However, it is important to coordinate the customer processes of the two units in order to provide quality service to the clients and create business benefit for the corporation.

The two business units and their clients constitute a network. Networks have been defined in many different ways (Möller et al., 2004). We define a network as a group of three or more actors that are in exchange relationship. In reality, the case network providing the service to the comprehensive schools is larger, constituting additionally of the mother corporation, educational administration, municipalities, and other content providers to the e-learning environment. We focus on the relationships that are in the core of the service process.

We conducted two simulation projects with our case network that underwent a substantial progress in the collaboration relationship. The practical development objective of the first simulation project was to create a common way of operating in order to build a consistent image of the products and services of the publisher corporation in the eyes of the common customers. This objective was defined together by the managements of the two business units and the researchers. Since there had not been much collaboration between the units before the simulation project started, and since the interviews revealed some 
attitudinal barriers, the most important task of the researchers was to identify needs and opportunities for collaboration as well as start building common understanding between the competing business units. The lack of common understanding was recognized by the management of the business units already before the interviews which then supported this view. The simulation day was designed to increase knowledge sharing and sense-making as well as to generate ideas for developing collaboration between the two business units. In the feedback session and in some informal meetings, people from the case organizations reported a change towards increasing efforts for cooperation on the grassroots level as well as a more positive climate towards collaboration (Jaatinen et al., 2005).

Once the people in the business units were more attuned to collaboration, the second simulation project could concentrate on developing practical solutions for collaboration. The management of the business units together with the researchers defined the practical objective for the second simulation project as the development of a common service process for the units in order to coordinate their own customer processes as well as to provide better service for customers. The simulation day focused on defining the common process as well as generating ideas for future development. This time, business units adopted the innovations immediately and reported successes already in the feedback session one month after the simulation day. In the feedback session, people were actively engaging in solving problems and taking responsibilities of carrying out agreed steps in the collaboration. A third simulation project was planned to tackle new processes of collaboration.

\section{Methods}


Our study applies abductive reasoning within a constructive action research paradigm in developing theories and models through multiple-case studies. Abductive reasoning can be described as a process, starting with a clue and proceeding to develop a theory through steps of deduction, to test it in empirical reality and steps of induction to generalize from empirical reality (Grönfors, 1985). It is a continuous cycle increasing the value of a theory. In this section, we describe first the research strategy and design and, then, the selected data collection and analysis methods in more detail.

Constructive research aims at developing a solution to a practically relevant problem by applying theoretical knowledge and at demonstrating the functioning and innovativeness of the solution developed. The success of constructive research can be evaluated by a weak or strong market test. To pass the weak market test, the solution has to be applied in managerial decision-making. To pass the strong market test, the application of the construction has to produce better financial results in the business unit (Kasanen et al., 1993).

Action research is a diverse field of approaches to scientific inquiry but these approaches share certain characteristics. Action research studies the impact of deliberately induced changes in an existing system in real time. Action research aims both at solving a practical problem and contributing to science. An action researcher participates actively in a development effort by organizational actors and collects data for scientific analysis and theory building at the same time. The scientific paradigm applied is hermeneutic, and requires appropriate quality criteria (Gummesson, 2000).

In this study, the theoretical framework of common understanding represents a construction that is developed to pass the market tests. The framework was applied as a 
planning paradigm for the first simulation project and the framework itself was developed based on our learning experiences and the collected data. We chose the framework of common understanding as the theory to be developed in our case because of its relevance to the problem the case organizations were facing. In the second project, we observed the role of the creation of common understanding in the later phases of the development effort to achieve better coordination in the case companies.

The original framework of common understanding was developed in two cases of networked product development between companies participating in process development simulations in SimLab as part of the R\&D Net project during the years 2000-2003 (Mäkelä, 2002; Hirvensalo et al., 2003). The findings reported in this paper concern a different type of context, namely networked service provisioning which is why we expected differences to appear in the data. The data for this study was collected in the Co-Create project (2003-2006) focusing on the co-creation of business models in company networks.

A case study investigates a contemporary phenomenon in its context. It is an empirical research strategy that can involve one or multiple cases as well as several units and levels of analysis within a single case study. Comparison between cases is achieved through replication logic (Yin, 1989). Building theory from case studies is achieved through a process consisting of a definition of research focus and potentially important constructs, theoretical sampling of cases, specifying methods to reach multiple types of evidence in multiple ways, ensuring an overlap of data collection and analysis, two dimensional analysis focusing on within-case analysis and cross-case comparison, iteration between an emergent theory and empirical evidence as well as replication of cases and 
understanding of relationships, comparison with previous research, and theoretical saturation (Eisenhardt, 1989).

This study compares evidence from one case to evidence from two cases that provided the empirical ground for developing the original framework of common understanding. The phenomenon studied is common understanding between collaborators, and the context is networked business. The level of analysis of the communication was discussion topics.

The main data collection and analysis methods were qualitative, including semistructured interviews, observation of group discussions during a simulation project, and a questionnaire. The participants to the interviews, simulation, and survey included people from different organizational levels from both the companies' and clients' side. Additional sources of information included documents provided by the companies or created during the simulation project such as process charts and management presentations on business models and objectives. The study was conducted by a team of three researchers, including the authors of this paper, which provides for multiple perspectives in each phase of the research process.

\section{SimLab ${ }^{\mathrm{TM}}$ method}

The constructive action research strategy was applied as part of business process simulations conducted using the $\operatorname{SimLab}^{\mathrm{TM}}$ method. The $\operatorname{SimLab}^{\mathrm{TM}}$ method is a registered business process development method developed in innovation action research by SimLab researchers. The method consists of the 7-step process of setting objectives, business process modeling, interviews to refine the process model, preparation of the simulation day, the simulation day, data analysis, and feedback (Smeds, 1994, 1997; 
Smeds, Haho and Alvesalo, 2003; Forssen and Haho, 2001; Haho 2002). The simulation day is an interactive, participative group simulation involving key people in the business process and facilitated by SimLab researchers (Smeds et al., 2006). During the day, a collaborative business process is discussed through and the raised development suggestions are focused on in group works. The simulation day provides organizations an interactive learning environment and functions as a platform for building common understanding (Jaatinen et al., 2005). The 7-step process of the simulation method provides research a structured way of data collection and an opportunity for theory testing and development. The simulation projects are managed together by the researchers and the representatives of the participating companies. The researchers are responsible for the operative level.

The simulation projects conducted during the Fall 2004 and Spring 2005 focused on identifying possibilities for collaboration and on developing the collaboration and coordination between the two business units of the publisher corporation. Both the projects consisted of a process following the seven steps described above. The kick-off meeting of the first project in September 2004 was participated by the top management of the two business units and the key people. It was accompanied by a separate kick-off held for the personnel of the business units. The process modeling sessions involved a few new employees central to the process of collaboration. Three cases were selected as examples of collaboration opportunities, and process models were created to support discussion in the simulation day. In parallel with process modeling, 17 people were interviewed to identify the state of common understanding and the opportunities for collaboration. Altogether 41 people participated in the simulation day. The group 
included 20 teachers who acted also as sales representatives of the publisher organization. These teachers were able to provide the customer point-of-view to the topics discussed during the simulation day. The simulation day program consisted of discussions on the goals and customer thinking of the business units, the process discussions, and group works on service concepts, good service, communication between the units, and opportunities for collaboration. In the end of the day, a research questionnaire was administered. The project lasted 6 months and ended with a feedback session in March 2005.

The second simulation project started right after the first one in April. The kick-off meeting was participated by the management of both the business units. The development of a common service process was set as the goal of the project and required one process modeling session with key people. The process model was refined in the following interviews with 6 people. The simulation day gathered together 27 people from the case organizations. The program consisted of a customer presentation, demonstration of the elearning environment, process discussion, and group works on good customer service, marketing messages, service concepts, and collaborative service process. The project ended with a feedback session in May 2005.

The observation data consists of group discussions during each step of the simulation projects. Notes were collected from meetings, and they were digital-recorded. The simulation days were video-taped. The data was used for understanding the change process and for triangulation with other types of data.

\section{Interviews}


The interviews conducted were designed to achieve two purposes: to solve the practical problem of coordination of action of the two business units and to explore the elements and state of common understanding as well as the role of common understanding in coordination. The method applied was a semi-structured interview technique in which discussion concentrates partly on predetermined topics and partly on topics that emerge during the interview and seem relevant for the solving of the practical problem or theory building (See e.g. Merton et al., 1956; Nachmias and Nachmias, 1981; Hirsjärvi and Hurme, 1985).

The first round of interviews was conducted in the beginning of the first development project during a period of three weeks. We interviewed people from both of the business units and on different levels in each. Altogether 17 people were interviewed, 10 from the school book unit and 4 from the e-learning unit (See Appendix 1 for the list of topics.). In addition, 2 teachers and 1 rector of one comprehensive school were interviewed to gain an insight into the perspective of the clients of the two business units.

The five additional interviews conducted in May 2005 focused on the issue of coordination. Three of the interviewees came from the management of the school book unit and one from the management of the e-learning unit. One interview was a pairinterview which was participated by the head of the school book unit's customer service and the head of the e-learning unit's customer service. The topics of the interviews varied according to the role of the interviewee in the organization. (The list of topics is provided in the Appendix 3.)

The interviews were digital-recorded and transcribed. The analysis of interview data followed a process of reading through the transcriptions, marking relevant pieces of text, 
gathering, and clustering marked pieces of text to produce a list of elements of common understanding.

\section{The questionnaire}

The questionnaire was designed to evaluate the effects of the simulation method as well as to collect evidence on the elements of common understanding. The questionnaire was applied in the end of the first simulation day to all the participants from the two business units of the publisher corporation: altogether 21 people, 13 from the e-learning unit, and 9 from the school book unit. Respondents were instructed to fill in the questionnaire and return it to a researcher before leaving the simulation room. The questionnaires were anonymous, and this was communicated explicitly. The questionnaire is included in the Appendix 2.

The questionnaire consisted of three structured questions (2-4) applying the common framework of common understanding presented by Mäkelä. The operationalization was based on Mäkelä's study and the characteristics of the studied case. The purpose of the five open-ended questions was to collect evidence that did not fit with the original framework. The questionnaire provides qualitative evidence on the elements central in creating common understanding. It describes the opinions of the participants to the simulation day. The sample corresponds quite well to the central actors in the case, because the participants to the simulation were selected on that basis.

The questions 2 to 6 can also be used for evaluating the simulation day. The questionnaire provides evidence on how the simulation increased common understanding between the business units, according to participants' subjective evaluation of the effects of the day on their own opinions and attitudes. In the first three structured questions, the 
respondents were asked to rate how much they received important and relevant information and how it affected their understanding of the topics and trust toward the partner. The evidence from the open-ended questions describes the usefulness of the topics discussed in the simulation and the missing topics that would have been important from the viewpoint of the participants. This provides an evaluation of the program of the simulation day.

The data from Likert-scale questions was analyzed as averages. The responses to openended questions 5-7 were analyzed on the level of topics and their frequency of appearance. The responses to the open-ended question 8 were classified and used to create a holistic picture of the effectiveness of the simulation day. Question 9 was used to triangulate with question 4.

\section{Findings and discussion}

First research objective: Towards a new framework of common understanding

Findings concerning the first research objective were derived from the data gathered during the first simulation project. The first simulation project set out to identify opportunities and threats for collaboration as well as to build common understanding about common business. The development of a common way of operating could only follow after some common understanding was created. Since there seemed to be little common understanding between the companies, we decided to explore the general theoretical framework of common understanding in an indirect way, by asking the interviewees to tell what could help them to collaborate and why there was almost no cooperation despite the clear signal from the management. We classified the ideas and reasons provided, and reached 8 categories describing elements of common 
understanding: understanding customer needs, open communication, common values, win-win model, common goals, common service offering, common operational model, and knowing each other (Jaatinen et al., 2005).

The questionnaire applied after the simulation day provided us additional data which we used to analyze common understanding. The open ended questions asked the participants to identify important topics of knowledge that the partners should share and agree on for the collaboration to start smoothly. Ten categories emerged defining elements of common understanding: common goals, common operational model, common process of planning, roles and responsibilities, open communication, common service offering, common and own business models, common customer's needs and fulfillment, knowing each other, and common language (Jaatinen et al., 2005).

When the two lists were contrasted, we noticed considerable overlap between them and proposed an integrated categorization for common understanding in this case: customer needs, common business model, common service offering, common operational model, common goals, knowing each other, and common values and language. The categories of common values and language were combined. Also, the categories of win-win model and common and own business models were combined to form a category common business model. The category common operational model includes earlier categories of common operational model, roles and responsibilities, and common process of planning (Jaatinen et al., 2005).

Since we studied contents of communication, the category open communication was left out. The lack of communication between the units seemed to have interfered with the discussion in this case. Openness of communication describes the way or the amount of 
communication. It might also be related to the lack of trust and be combined with the category knowing each other.

When the case data was compared with the original model presented by Mäkelä, we noticed some clear differences. Our case data provided supportive evidence for all the categories but suggested refinement of the category labeled trust. Based on our findings trust is more of a consequence of knowing each other and each other's competences. Trust is not a shared meaning but it can be a result of it. There is no generally accepted definition of trust among the researchers but the definitions commonly characterize trust as a confident expectation or willingness to be vulnerable (Rousseau et al., 1998; Grunig \& Huang, 2000). These expectations concern the intentions and behavior of the trustee (Berecca, 1998). In the study of inter-organizational trust, trust has been defined to be related to a partner's ability to perform and his intensions to do so (Nooteboom, 1996). Thus, collaborators need to define the common resources and the added value of combined competences in order to increase trust. The difference to the original model is that the category consists not of beliefs but the objects of beliefs and is labeled accordingly.

Also, the case data suggested some new categories. The category of common business model consists of shared understandings about the way a network is responding to the needs of the common customers and the earnings logic behind it. In the service context, customer's role is emphasized. This is because the customer is part of the service process (Edvardsson and Olsson, 1996). Service process consists of interaction between the service provider and the customer (Grönroos, 1998). The category of external environment includes understanding customer needs but it also gives attention to other 
factors such as competition, subcontractors, legal environment, and resource acquisition. The context for developing the original model was two collaborative R\&D projects focusing on new technology creation with no direct use for consumers. This might explain why consideration of external environment did not emerge as a topic deserving of its own category. Customer needs were discussed but only related to common goals in one case.

The importance of understanding each other's earnings logic was raised as a crucial trigger for collaboration during the first simulation project. Analysis of data gathered both before and after the simulation revealed discussion on each other's business models and the win-win model as one of the most important topics to discuss when creating collaboration. That would help the collaborators to identify useful areas of collaboration and alleviate possible suspiciousness. Since the context of the original model was technical development for customer company's internal processes or machinery, consideration of business models or earnings logic were in minor role. We considered the inclusion of this category important because we aim at developing a general theory for business processes that begin and end with end-customers.

The new framework of common understanding consists of the following elements (Figure 1): 1) shared ways of thinking, 2) shared environment, 3) shared goals, 4) shared business model, 5) shared operational model, 6) shared knowledge, and 7) shared competences and resources (Jaatinen et al., 2005).

Take in Figure 1. The new framework of common understanding. The second research objective: the role of common understanding in coordination 
The findings concerning the second research objective were derived from the data gathered during the second simulation project. The second simulation project focused on developing a common service process for the two business units. The new process model describes how the two units can collaborate and coordinate their operations and activities in a common service process which links the two organizations' own customer processes. The common service process is trying to integrate the planning of marketing, promotion activities, operations of customer service centres, and electronic sales and distribution (Södergård, 2005).

The coordination mechanisms selected by the case organization included integrating the units under the same business and a common head, common planning of marketing, and training people on the other unit's products and services. Of these mechanisms of coordination, the latter two appear in the process chart. However, it is implied that lots of coordination activity has to be executed by informal communication through lateral linkages between people dealing with similar problems in their work. Special attention was put on customer service centers that the units plan to integrate into one call center. Also, the common service process itself is a communication tool for coordination (Södergård, 2005). Reciprocal interdependence sets high requirements on communication for coordination (Thompson, 1967). The problems of coordination that remain unsolved by other mechanisms are best handled by horizontal communication (Galbraith, 1977; Mintzberg, 1979; Conrad and Poole, 2002).

The common service process is actually a decision-making and communication process focusing on non-routine tasks which explains preference of the selected coordination mechanisms. According to Mintzberg (1979), the more non-routine the task, the more 
suitable the mechanisms of standardization of output and skills as well as mutual adjustment.

Along the process of organizational development and especially during the simulation days, we noticed that topics related to the premises of collaboration, i.e., elements of common understanding, were raised repeatedly and related problems solved anew (see Figure 2). The discussion topics of the first simulation day centered around the business models, customer needs as well as the services and products of each unit, the possible areas of collaboration, ways of developing communication between the units, and the coordination of customer relations and marketing messages. This was partly preplanned and partly spontaneous. However, the same topics surfaced on the second simulation day even though it focused more on building a common process. The common strategy was still unclear. There was disagreement on service concepts, service packages, and delivery channels. This was a reason why it was not possible to create common marketing messages. Many discussions were concluded by agreement that this issue is still unresolved and should be dealt with before action. The foundations of collaboration had to be built before the walls, walking paths, and a roof could be designed. There was a need to understand each others business and the common business before common and separate operations could be planned. Thus, it was important to create shared meanings concerning common business in order to create mechanisms of coordination on the operative level.

Take in Figure 2. The dynamic framework of common understanding as a coordination mechanism (Jaatinen and Södergård, 2006). 
This emphasis on building common understanding is in accordance with Perrow's (1986) claim that the more non-routine the task, the better the mechanisms of premise or unobtrusive controls. Once the common premises have been created, they will coordinate people's actions.

In addition, the new process model actually defined the meetings to be held every year for recreating common understanding and for solving upcoming coordination challenges. This was required because the business environment and the services are constantly changing. These meetings provide an arena for communication through which participants will redefine the objectives and areas of collaboration as well as choose relevant means for collaborative planning and action in that year. The decisions are based on information and knowledge shared and created concerning the changes in the business environment and business goals. This process reminds us of the sense-making recipe provided by Weick (1979), and it provides for shared meanings concerning central issues in collaboration.

\section{Conclusions}

We presented a new framework of common understanding in networked business. It should be further developed in new cases of networked service provisioning between business units. It would also be interesting to apply it in new kinds of contexts and different types of networks. Future study could also explore more closely the process of creating shared meanings defining collaboration and the nature of communication required. The new framework of common understanding can be used by the management of the case organizations in future cases of collaborative service development for selecting important topics for discussion in the beginning of collaboration. 
We described coordination in a network as a process of recreation of common understanding and described the role of common understanding in achieving coordination. Our findings suggest that common understanding is an important mechanism of coordination in business networks, and the creation of shared meanings lays the ground for collaboration. Since the business environment is constantly changing, the shared meanings have to be recreated continuously. This view should be further developed in subsequent studies. It would also be interesting to explore sense-making in parallel with other mechanisms for coordination, and study more closely the effectiveness of different mechanisms in solving different problems of coordination.

This case study is part of a research program using a multiple-case design within a constructive action research strategy. By analytic generalization, we believe new cases can be found in which our findings are applicable. This study provides only a weak market test: the original framework of common understanding was applied in the development project and the new insights gained on the elements and the role of common understanding were incorporated in the plan as they were recognized. However, the decision was made by the researchers and the acceptance gained from the organizations was not as strong as if the management itself applied a construction in their organization. The quality of our action research was increased by the close connection between the practical and theoretical problem solving, a structured change process designed in collaboration between the researchers and people in the case organizations as well as the real-time observation of changes in the phenomenon and the collection of feedback from the participants. Also, the researchers were continuously assessing and making conscious their role in the project. We conducted the interviews in a passive mode. In the overall 
project, however, we listened to the management of the two case organizations and gave suggestions on the objectives of the development project and concrete action plan. Finally, the study resulted in new theoretical implications as well as a change toward a desired goal in the client organization.

Lincoln and Guba (1985) provided four criteria of soundness that are also applicable to the evaluation of this study. The credibility of this study was increased by active collaboration between the management of the case organizations and the researchers as well as by the triangulation of methods, informants, sources, and researchers. The transferability criterion was met by describing the context, case, and processes in necessary detail. The dependability criterion referring to the changing social world and the ability of the researcher to adapt is crucial in action research. Since the researchers were active participants in the development project and followed changes continuously, adaptation to the situations, setting, and conditions was possible to a great extent. We also provided descriptions of the process and changes in this paper. We aimed at increasing confirmability by presenting detailed enough descriptions and explanations of operationalization, data collection, and analysis as well as linking data to the development of the framework of common understanding.

The manager of the e-business unit described the change process of the case organizations in the end seminar of the Co-Create project in the following way: In the beginning, the people in the units could not have been less interested in collaboration. After the first simulation project, the people acted as if they understood each other and collaborated. After the second simulation project, they were honestly willing to 
understand each unit's side but mistook many things. It was only step by step up to this speech that people started understanding each other right.

\section{Acknowledgements}

The research reported in this paper has been conducted during two research projects in SimLab: the R\&D Net (2000-2003) and the Co-Create (2003-2006). The data published in this paper originates from the latter project. The authors are grateful for the creative research effort of the whole Co-Create research team which has made this paper possible. The research is financially supported by the following organizations which are gratefully acknowledged: Finnish Funding Agency for Technology and Innovation (Tekes) and the pilot companies.

\section{References}

Aula, P. (1999), Organisaation kaaos vai kaaoksen organisaatio (Chaotic organization or organization of chaos, in Finnish), Loki-kirjat \& Pekka Aula, Helsinki, Finland.

Aula, P. (2000), "Dynaaminen duo. Organisaation kulttuurit ja viestintä” (Dynamic duo. The cultures of organizations and communication, in Finnish), in Aula, P. \& Hakala, S. (Eds.), Kolmet kasvot (Three faces, in Finnish), Loki-kirjat, Helsinki, Finland.

Berecca, M. (1998), Nature, antecedents, and consequences of trust within organizations: the multilevel analysis within the multinational corporation, Doctoral dissertation, University of Maryland, USA.

Choo, C.W. (1998), The knowing organization: how organizations use information to construct meaning, create knowledge and make decisions, Oxford University Press, NY.

Conrad, C. (1994), Strategic organizational communication: Toward the twenty-first century, $3^{\text {rd }}$ ed., Harcourt Brace, Fort Owrth, TX.

Conrad, C. and Poole, M.S. (2002), Strategic organizational communication: In a global economy, $5^{\text {th }}$ ed., Harcourt Brace, Fort Owrth, TX.

Czarniawska-Joerges, B. (1992), Exploring complex organizations: A cultural perspective, SAGE, Newbury Park, CA.

Edvardsson, B. and Olsson, J. (1996), "Key concepts for new service development", The Service Industries Journal, Vol. 16, No. 2, pp. 140-164.

Eisenhardt, K.M. (1989), "Building theories form case study research", Academy of Management Review, Vol. 14, No. 4, pp. 532-550.

Forssén, M. and Haho, P. (2001), "Participative development and training for business processes in industry: review of 88 simulation games ", International Journal of Technology Management, Vol. 22, No. 1/2/3, pp. 233-262.

Galbraith, J.R. (1977), Organization Design, Addison-Wesley, Reading, Massachusetts. 
Grunig, J. and Huang, Y. (2000), From organizational effectiveness to relationship indicators: antecedents of relationships, public relation strategies, and relationship outcomes, in Ledingham, J. A. and Bruning, S. D. (eds.), Public relations as relationship management, Lawrence Erlbaum Associates, Mahwah, NJ.

Grönfors, M. (1985), Kvalitatiiviset kenttätyömenetelmät (Qualitative methods for fieldwork, in Finnish) $2^{\text {nd }}$ ed., WSOY, Juva, Finland.

Grönroos, C. (1998), Nyt kilpaillaan palveluilla (Now services compete, in Finnish), $4^{\text {th }}$ ed., WSOY, Porvoo, Finland.

Gummesson, E. (2000), Qualitative methods in management research, $2^{\text {nd }}$ ed., SAGE, Thousand Oaks, CA.

Haho, P. (2002), Simulointipeleihin perustuvan kehittämismenetelmän hyötyjä liiketoimintaprosessien kehittämishankkeissa. Hyvän kehittämisjärjestelmän menestystekijöitä (Benefits of the simulation game based development method in business process development projects. Success factors of a good development method, in Finnish), Publications, Dissertation Series 1, Espoo, Helsinki University of Technology SimLab.

Hannus, J. (2004), Strategisen menestyksen avaimet. Tehokkaat strategiat, kyvykkyydet ja toimintamallit (The keys to strategic success. The effective strategies, competences and business models, in Finnish), Gummerus, Jyväskylä, Finland.

Hirsjärvi, S. and Hurme, H. (1985), Teemahaastattelu (Theme interview, in Finnish), $3^{\text {rd }}$ ed., Gaudeamus, Helsinki, Finland.

Hirvensalo, A., Evokari, J., Feller, J., Pekkola, K., Turunen, P. and Smeds, R. (2003), $R \& D N e t$ Final report. Process Innovation in Collaborative R\&D. Lessons Learnt from the Telecommunications Industry, Helsinki University of Technology SimLab, Publications, Report Series 2, Espoo.

Jaatinen, M., Södergård, R. and Peuhkurinen, M. (2005), "Learning in networked service provisioning”, in New approaches to learning, studying and teaching, (eds.) Smeds, R., Riis, J., Haho, P. and Jaatinen, M., proceedings of the $9^{\text {th }}$ workshop of the IFIP WG 5.7 Special Interest Group on Experimental Interactive Learning in Industrial Management, June 5-7, 2005, Espoo, Finland.

Jaatinen, M. and Södergård, R. (2006), Common Understanding and Coordination. In Jaatinen, M., Hirvensalo, A., Smeds, R., Södergård, R., Valkeapää, E., Koriseva, M., Seppänen, J. and Soback, D. (eds.) 2006, Co-Create Final Report. Co-Creation of Business Models in Company Networks. Customer Orientation, Innovation, and Common Understanding in Collaborative Business. Espoo: Helsinki University of Technology, SimLab Report series 15, pp. 70-74.

Kaplan, R. (1998), "Innovation action research: creating new management theory and practice”, Journal of Management Accounting Research, Vol. 10, pp. 89-118.

Kasanen, E., Lukka, K. and Siitonen, A. (1993), "The constructive approach in management accounting research", Journal of Management Accounting Research, Vol. 5, pp. 243-262.

Lawrence, P.R. and Lorsch, J.W. (1967), Organization and environment, Irwin. Lincoln, Y. and Guba, E. (1985), Naturalistic inquiry, SAGE, Beverly Hills, CA.

Merton, R.K., Fiske, M. and Kendall, P.L. (1956), The focused interview - A manual of problems and procedures, The Free Press, Glencoe, I11. 
Mintzberg, H. (1979), The Stucturing of Organizations, Prentice-Hall, Englewood-Cliffs, N.J.

Mäkelä, K. (2002), Yhteisen ymmärryksen muodostuminen. Organisaationkulttuurin, viestinnän ja tiedon yhteisvaikutus yritysten välisissä T\&K-projekteissa (Construction of common understanding. Interplay of organizational culture, communication and knowledge in inter-company R\&D-projects, in Finnish), Master's thesis, Department of Communication, University of Helsinki. (unpublished)

Möller, K., Rajala, A. and Svahn, S. (2004), "Strategic business nets - their type and management", Journal of Business Research, Vol. 58, pp. 1274-1284.

Nachmias, D. and Nachmias, C. (1981), Research methods in the social sciences, $2^{\text {nd }}$ ed., St. Martin's Press, New York.

Nonaka, I. and Takeuchi, H. (1995), The Knowledge-creating company: how Japanese companies create the dynamics of innovation, Oxford University Press, New York.

Nooteboom, B. (1996), Trust, opportunism, and governance: a process and control model, Organization Studies, Vol. 17, No. 6, pp. 985-1010.

Perrow, C. (1986), Complex organizations, $3^{\text {rd }}$ ed., McGraw-Hill, New York, NY.

Rousseau, D.M., Sitkin, S.B., Burt, R.S. and Camerer, C. (1998), Not so different after all: a cross-discipline view of trust, Introduction to special topic forum, Academy of Management Review, Vol. 23, No. 3, pp. 393-404.

Schein, E.H. (2004), Organizational culture and leadership, $3^{\text {rd }}$ ed., Jossey-Bass, San Francisco, CA.

Smeds, R. (1994), "Managing Change towards Lean Enterprises”, International Journal of Operations and Production Management, Vol. 14, No. 3, pp. 66-82.

Smeds, R. (1997), "Organizational Learning and Innovation through Tailored Simulation Games: Two Process Re-engineering Case Studies”, Knowledge and Process Management, Vol. 4, No. 1, pp. 22-33.

Smeds, R., Haho, P. and Alvesalo, J. (2003), "Bottom-up or top-down? Evolutionary change management in NPD processes ”, International Journal Technology Management, Vol. 26, No. 8, pp. 887-902.

Smeds, R. Jaatinen, M., Hirvensalo, A. and Kilpiö, A. (2006), SimLab process simulation method as a boundary object for inter-organizational innovation. Paper presented to the $10^{\text {th }}$ International Workshops on Experimental Interactive Learning in Industrial Management, Trondheim, Norway.

Södergård, R. (2005), Kahden liiketoimintayksikön yhteistoiminnan kehittäminen: palveluprosessien yhdistäminen ja koordinointi (Developing collaboration between two business units: integrating and coordinating the service processes, in Finnish), Masters thesis, Helsinki University of Technology, Department of Computer Science and Engineering, SimLab Report Series 12, Espoo, Finland.

Thompson, J.D. (1967), Organizations in Action, McGraw-Hill.

Weick, K.E. (1979), The Social Psychology of Organizing, $2^{\text {nd }}$ ed., Random House, New York, NY.

Weick, K.E. (1995), Sensemaking in Organizations, SAGE, Thousand Oaks, CA.

Wenger, E. (1998), Communities of Practice, Cambridge University Press.

Yin, R. K. (1989), Case study research: design and methods, SAGE, Newbury Park, CA. 


\section{Appendix 1. Interview topics of the first simulation project}

\section{General list of discussion topics:}

1. Introduction

- how you were told about the interview?

- describe your roles and responsibilities in the organization

- who are your clients and when do you meet them?

- what are your products or services?

\section{Planning process}

- how are marketing plans created in your unit?

- what is the most important objective in marketing your products or services?

- what kind of information do you need for making the plans?

- in which phases of the planning process could the other unit be involved and how?

- what and whom do the plans affect?

\section{Case}

- describe a case of collaboration in which you meet a common client

- how do you prepare for the meeting

- what kind of information you need and from whom

- what happens during the meeting

- what happens afterwards

- who you should inform after the meeting

- how could you involve the other unit or present its products

\section{Collaboration}

- what kinds of opportunities are there to collaborate?

- what kind of collaboration would benefit you in your work?

- what kinds of things would support collaboration?

- what kind of things hinder you from cooperating with people in the other unit?

\section{Communication}

- how you were told about the birth of the e-business unit?

- what kind of information you have got on the other unit and its products or services?

- what kind of information you would have liked to get?

- through which channels do you get this information?

\section{Customer perspective}

- how do you get information on the needs of your clients?

- how do you use this information?

- how are customers needs taken into account today?

- what kinds of questions do the customers ask on the other units products or services?

- how do you respond to these questions?

- what kinds of customer information systems do you use in your work

\section{Is there something else you would like to say or ask?}

\section{Additional topics for the management:}

- describe the organization and the processes of your unit?

- what kinds of objectives are there for the collaboration between the units?

- what kind of collaboration is there today?

- how should collaboration be developed in the future?

- what kinds of factors has to taken into account when developing collaboration between the units? 
Appendix 2. Questionnaire

(The original questionnaire was in Finnish. This is a translation of the questionnaire.)

Please respond to the following questions by selecting the suitable alternative according to your opinion.

1. Which unit you come from?

I am a consultant, (the school book unit)

I come from (the school book unit)

I come from (the electronic learning environment unit)

2. How much information useful for your work did you get on the following topics today? Give your evaluation on the scale $0-5$, where $0=I$ do not know, $1=$ very little, $2=$ =quite little, $3=$ reasonable amount, $4=$ quite a lot, $5=$ very much.

The other unit's ways of thought (concepts and values)

The other unit's ways of operating (tasks and practices)

The other unit's products and services

The other unit's business goals

The other unit's people's competences

Concepts and values behind collaboration between the units

Peoples roles in collaboration and the common ways of working

The object and content of collaboration

The goals of collaboration

Competences central in collaboration

3. How much did the discussion day help you to understand the following topics? Give your evaluation on the scale $0-5$, where $0=I$ do not know, $1=$ not at all, $2=$ little, $3=$ somewhat, $4=a$ lot, $5=$ very much.

The other unit's ways of thought and language

The other unit's ways of operating

The other unit's people work

The other unit's business goals

Concepts and values behind collaboration between the units

Common ways of operating

The contents of collaboration

The goals of collaboration

4. How would you evaluate another company's actions and people? How well do the following sentences correspond to your opinions? Give your evaluation on the scale $0-5$, where $0=I$ do not know, $1=$ not at all, $2=$ =little, $3=$ to some extent, $4=$ =quite well, $5=$ very well.

I can trust that they have the competences to accomplish their role.

I can rely on them to keep their promises.

I can rely on them to be genuinely interested in collaboration.

I can share knowledge with them openly.

The development day increased my trust in the other unit.

Give a short answer to the following questions based on your opinion.

5. Which of the discussion topics of the simulation day were important for collaboration?

6. On which topics would you have needed more information?

7. What things should be agreed on for collaboration to flow smoothly?

8. How did the simulation day affect your attitude towards collaboration? Do you now see more or less opportunities for collaboration? Why?

9. How do you think trust could be built between the companies? 


\section{Appendix 3. Interview topics of the second simulation project}

\section{General list of discussion topics}

(The original questions were in Finnish. This is a translation of the questions.)

\section{Introduction}

- this interview is about managing common customerships

- describe your own organization and your role in it.

- what things are you responsible for?

\section{Planning}

- describe your organization's strategic marketing planning process

- are you planning the activities together with the other organization. Who do you think should plan it?

\section{Management and the structure of the organization}

- describe your organization's marketing management, what about the strategic management

- what is the structure of the new corporation like? Could you draw it for us?

- how could the common activities be managed? Who could manage the common operations?

\section{Coordination inside your own organization and coordination of common activities}

- how could different players be managed and lead? How could it be improved? Give us some examples.

- what can be gained by using different modes of coordination?

- how should work be coordinated?

- how are common activities being coordinated at the moment?

- how could common operations be coordinated?

\section{Decision making}

- how strategic/marketing decisions concerning customers/products/marketing are made?

- are decisions made together? If not, how the decisions could be made together?

\section{Communication and flow of information}

- describe the communication in your organization

- how could common communication be arranged in common operations?

- what information both units need in order to accomplish the objectives?

- how should communication and flow of information be arranged?

\section{Common objectives}

- what is your organization's object?

- what kind of objectives do you see for these two organizations?

- how could common objectives be reached?

- how are common objectives defined? Who were present then?

\section{Trust}

- describe the atmosphere of the collaboration

- $\quad$ how could the atmosphere of the collaboration be improved?

- how did the common development day (10.1.2005) affect your cooperation?

\section{Integrating the contents (products and services)}

- where and how the contents of the products and services should be integrated? Who should be responsible for that?

\section{Creating selling arguments}

- how should the selling arguments be created? 
- $\quad$ who is responsible for creating common messages for common customers?

\section{Customer service}

- what kind of cooperation could benefit both organizations?

- $\quad$ do you have suggestions how the customer services could be improved and in what way?

\section{Service process map (showing map to the interviewee)}

- what do you think about the process map now, is it describing the future the way you see it? What should be added or removed from it?

- who should participate in different phases of the process?

- what things should be decided in different phases of the process? 


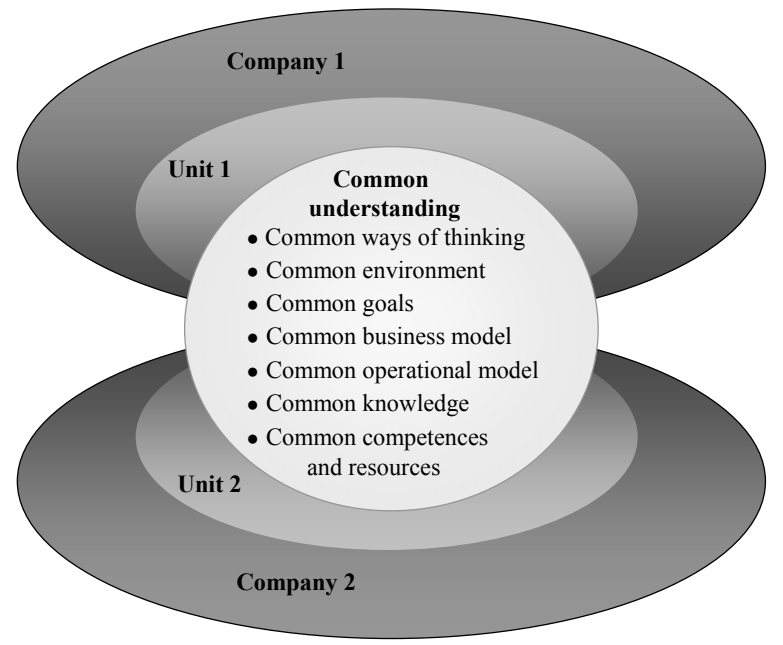

Figure 1. The new framework of common understanding

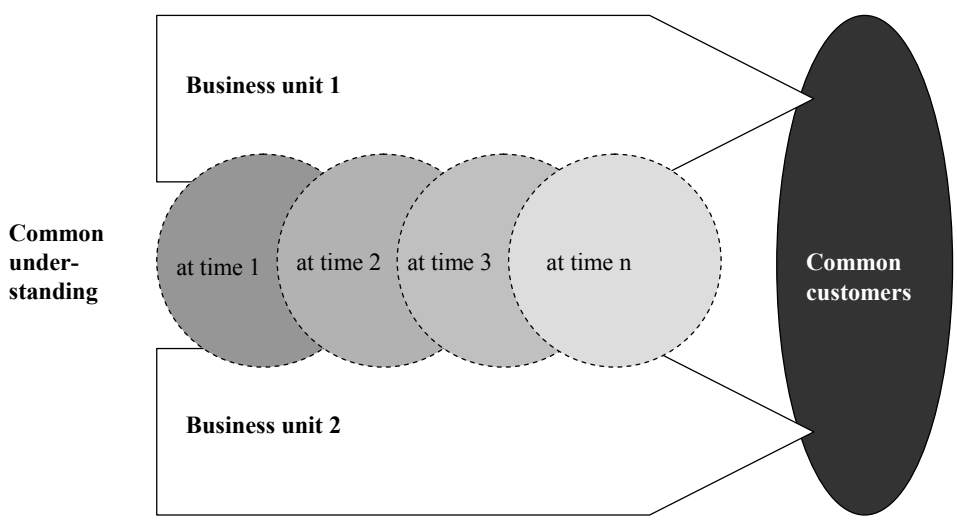

Figure 2. The dynamic framework of common understanding as a coordination mechanism (Jaatinen \& Södergård 2006) 